JRPB, Vol. 7, No. 1, Maret 2019, Hal. 17 - 23

DOI: $10.29303 /$ jrpb.v7i1.99

ISSN 2301-8119, e-ISSN 2443-1354

http://jrpb.unram.ac.id/

\title{
RANCANG BANGUN HOPPER OUT PUT CAMPURAN RAGI TEMPE DENGAN KEDELAI
}

\author{
Design and Construction of Hopper Output of Mixed Tempe Yeast with Soybean
}

\author{
Surya Abdul Muttalib ${ }^{1, *)}$, Agriananta Fahmi Hidayat ${ }^{1}$, Asih Priyati ${ }^{1}$ \\ ${ }^{1}$ Teknik Pertanian, Fakultas Teknologi PAngan dan Agroindustri, \\ Universitas Mataram \\ Email $^{*}$ : surya15@unram.ac.id \\ Diterima: Nopember 2018 \\ Disetujui: Maret 2019
}

\begin{abstract}
Tempe which is the leading commodity of Mataram City, West Nusa Tenggara is produced by the UMKM sector which still uses simple technology and methods. The use of labor resources in the field of production is still very high. Every production of $50 \mathrm{~kg}$ of raw materials requires a minimum of 2 workers. This is felt to be less efficient in the economic field. Various alternative efforts to increase production with the use of appropriate technology continue to be developed with the use of tempe yeast mixing machines with soybeans (inoculum process) which are proven to be able to improve time and labor efficiency. The design of the mixing machine that has been developed has weaknesses in the container side which are mixed results. Hopper technology is possible to greatly help UMKM tempe production to be more developed. The hopper developed in the study has a trapezoidal shape with dimensions of $50 \times 36 \times 10 \mathrm{~cm}^{3}$, the output part has a dimension of $10 \times 10 \mathrm{~cm}^{2}$. The developed hopper could be filled by $25 \mathrm{Kg}$ tempe. The highest performance results with a slope angle of $60^{\circ}$ by $18 \%$ yield and 2.14 seconds processing time. The yield of $18 \%$ caused by the high material water content of $59.99 \%$, which results in a high cohesive and adhesive force of the material. Therefore, modification using additional vibration is required.
\end{abstract}

Keywords: design, performance, yield, tempe

\begin{abstract}
ABSTRAK
Tempe yang menjadi komoditas ungggulan Kota Mataram Nusa Tenggara Barat diproduksi oleh sektor UMKM yang masih menggunakan teknologi dan metode sederhana. Pengggunaan sumber daya tenaga kerja dalam bidang produksi masih sangat tinggi. Setiap produksi $50 \mathrm{Kg}$ bahan baku membutuhkan minimal 2 orang tenaga kerja. Hal ini dirasa kurang efisien dalam bidang ekonomi. Berbagai upaya alternatif peningkatan produksi dengan penerapan prinsip teknologi tepat guna dikembangkan pada tahun 2017 dengan memproduksi mesin pencampur ragi tempe dengan kedelai (proses inokulum). Mesin pencampur yang dikembangkan tersebut terbukti mampu
\end{abstract}


meningkatkan efisiensi waktu dan tenaga kerja. Namun, Rancangan mesin pencampur yang sudah dikembangkan memiliki kelemahan pada sisi penampung hasil campuran (hopper). Penelitian ini bertujuan untuk merancang dan menguji kinerja hopper mesin pencampur ragi tempe dengan kedelai pada berbagai variasi kemiringan yakni $30^{\circ}, 45^{\circ}$ dan $60^{\circ}$. Hopper yang dikembangkan berbentuk trapesium dengan dimensi 50 x 36 x10 $\mathrm{cm}^{3}$, bagian output berdimensi $10 \times 10 \mathrm{~cm}^{2}$. Hopper yang dikembangkan terbukti mampu menampung inokulum tempe sebesar $25 \mathrm{Kg}$. Hasil unjuk kerja hopper tertinggi diperoleh pada sudut kemiringan $60^{\circ}$ dengan rendemen sebesar $18 \%$ dan waktu proses 2,14 detik. Hasil rendemen sebesar $18 \%$ disebabkan oleh kadar air inokulum tempe cukup tinggi sebesar 59,99\% yang mengakibatkan gaya kohesif dan adhesive dari bahan cukup tinggi sehingga ikatan antar partikel cukup kuat. Oleh karena itu, diperlukan modifikasi dengan penambahan penggetar.

Kata kunci: desain, performansi, rendemen, tempe

\section{PENDAHULUAN}

\section{Latar Belakang}

Peningkatan efisiensi dan efektifitas dalam kegiatan produksi harus sudah menjadi acuan dalam setiap kegiatan. Oleh karena itu, diperlukan suatu teknologi yang mampu menjawab setiap permasalahan yang dihadapi oleh UMKM khususnya di Kota Mataram.

Di Kota Mataram usaha tahu dan tempe berpusat di Kelurahan Kekalik. Berdasarkan keputusan Walikota Mataram Nomor 526/X/2009 tentang penetapan klaster industri kecil unggulan kota mataram, Kelurahan Kekalik memiliki posisi ke-3 sebagai produsen tempe dan tahu yakni sebanyak 227, dengan pengusaha tempe sebanyak 113, dengan kedelai untuk memproduksi tempe dan tahu mencapai 20 ton per hari dengan nilai investasi sekitar 10 juta rupiah (Keputusan Walikota Mataram Nomor 526/X/2009).

Umumnya industri tempe di Kelurahan Kekalik masih mengolah tempe secara tradisional. Pada setiap unit kegiatan pengolahan masih menggunakan alat sederhana dan dikerjakan oleh tenaga manusia. Salah satu proses pembuatan tempe yang memegang bagian penting penentu mutu tempe adalah proses pencampuran kedelai atau peragian tempe dengan kapang. Selama ini para pengrajin menggunakan sutil sebagai batang pengaduk, kedelai yang akan diragi diletakkan di atas terpal yang dibentangkan di atas lantai, pencampuran biasanya dilakukan oleh 2-3 orang.

Muttalib dkk., (2017) telah mendesain mesin pencampur ragi tempe dengan kedelai yang terbukti mampu menghasilkan tempe dengan kualitas seragam dan terjadi peningkatan efisiensi waktu pengerjaan di industri tempe hingga 300 persen. Awalnya dibutuhkan waktu 30 menit pencampuran, dengan mesin pencampur tersebut menjadi hanya 5 sampai 7 menit dengan kapasitas $30 \mathrm{Kg}$ bahan baku. Kendala yang masih muncul dalam desain mesin pencampur yang dikembangkan pada penelitian sebelumnya adalah tingkat higienitas produk yang dihasilkan masih kurang. Hal ini disebabkan hasil pencampuran ditempatkan di bakul kemudian dikemas menggunakan tangan oleh para pekerja. Oleh karena itu, diperlukan sebuah hopper yang memungkinkan bahan campuran ragi tempe dengan kedelai mampu dikemas secara baik.

Berdasarkan kerja mesin yang ingin dicapai, maka konstruksi mesin perlu untuk direncanakan dengan baik agar kerja mesin dapat dioptimalkan. Setiap komponen penyusun mesin dianalisis baik dimensi maupun fungsi dari masingmasing komponen. Penentuan dimensi dan fungsional mesin ini ditentukan 
dengan cara mengetahui atau merencanakan terlebih dahulu karakteristik mesin yang akan dibangun, sehingga dapat ditentukan komponen penyusun mesin dengan tepat. Analisis dimensi dan fungsional mesin diperlukan dalam perancangan mesin pencampur ini untuk mendapatkan hasil yang maksimal. Tujuan perencanaan analisis dimensi dan fungsional mesin atau alat adalah agar mesin atau alat yang dikembangkan dapat sesuai dan mampu meningkatkan kapasitas produksi (Saddam, 2012).

\section{Tujuan}

Tujuan penelitian yakni merancang dan mengembangkan suatu hopper mesin pencampur ragi tempe dengan kedelai.

\section{METODE PENELITIAN}

\section{Alat dan Bahan}

Alat dan bahan yang akan digunakan dalam penelitian ini yakni: Kedelai hasil perebusan yang siap diolah menjadi tempe, kapang (ragi tempe), mesin pencampur, besi kotak $3 \times 3 \mathrm{~mm}$, plat Stainless Steel dan moisture analizer.

\section{Metode}

Penelitian ini merupakan penelitian eksperimental dengan percobaan di laboratorium. Adapun bagan alir penelitian dapat dilihat pada Gambar 1.

Parameter sifat teknik inokulum campuran ragi tempe dengan kedelai (inokulum) sebagai dasar perancangan Hopper yakni:

Dimensi bahan, kadar air inokulum, angle of refuse dan massa jenis. Sedangkan parameter unjuk kerja yakni rendemen (\%) dan waktu tunggu campuran keluar dari hopper (detik).

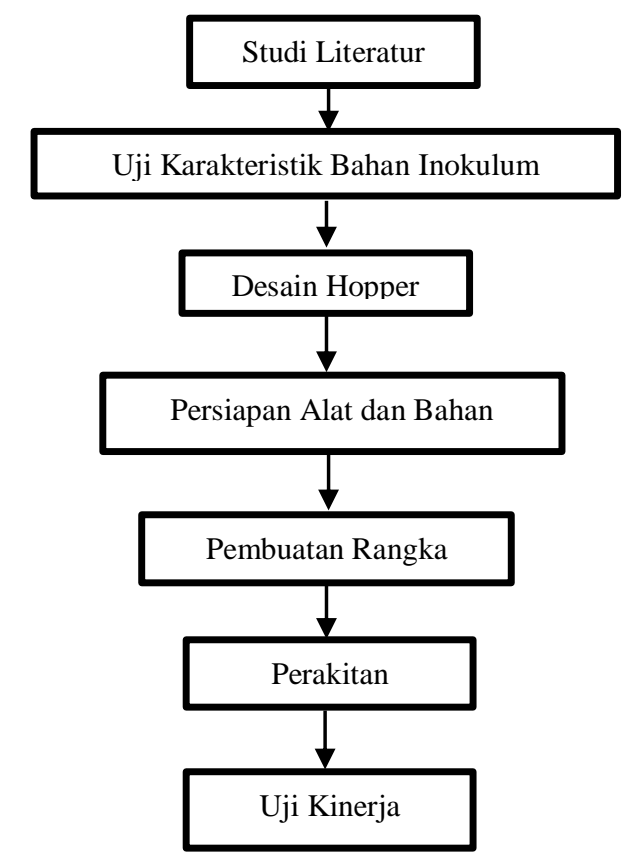

Gambar 1. Bagan Alir Penelitian

\section{HASIL DAN PEMBAHASAN}

Penelitian diawali dengan perancangan hopper yang disesuaikan dengan sifat atau karakteristik bahan kemudian melakukan unjuk kerja hopper yang dikembangkan.

\section{Karakteristik Bahan Campuran Ragi Tempe dengan Kedelai}

Dalam suatu sistem perancangan, perencaan mejadi titik kunci keberhasilan desain yang dikembangkan. Salah satu hal yang harus diperhatikan dalam perancangan suatu mesin tentu saja produk atau bahan yang diproses. Dalam penelitian ini, bahan yang akan diuji yakni bahan semi basah berupa kedelai bercampur ragi tempe yang sudah tercampur. Adapun rerata karakteristik kedelai pada proses pembuatan tempe yang digunakan sebagai bahan penelitian dapat dilihat pada Tabel 1. 
Tabel 1. Nilai Rerata Karakteristik bahan Campuran Kedelai dengan Ragi Tempe

\begin{tabular}{llll}
\hline No & Karakteristik & Nilai & Satuan \\
\hline 1 & Kadar Air & 59,57 & $\%$ \\
2 & Angel of Refuse & 28,79 & $\circ$ \\
3 & Dimensi & & \\
& *Panjang & 12,2 & $\mathrm{~mm}$ \\
& *Lebar & 6,8 & $\mathrm{~mm}$ \\
& *Tinggi & 3,2 & $\mathrm{~mm}$ \\
4 & Massa Jenis & 0,73 & $\mathrm{gram} / \mathrm{cm}^{3}$ \\
\hline
\end{tabular}

Karakteristik bahan menjadi acuan dalam perancangan dan desain hopper. Berdasarkan Tabel dapat dilihat bahwa kadar air bahan berada pada kisaran 60 persen, yang artinya bahwa bahan campuran kedelai untuk proses pengolahan tempe merupakan bahan semi basah. Kandungan air yang terkandung cukup tinggi yang memungkinkan mikroba dari jamur rizhoppus sp akan mampu tumbuh dengan baik (Koswara, 1995). Namun, bagi perancangan hopper kadar air yang tinggi akan menimbulkan gaya gesek antar bahan. Sementara stabilitas fisik produk pangan memiliki kaitan dengan kadar air kesetimbangan pada suhu tertentu (Adawiyah, 2006).

Berdasarkan pengujian karakteristik bahan (Tabel 1), diketahui angel of refuse sebesar $28^{\circ}$. Dengan demikian, sudut kemiringan hopper dimungkinkan yakni $60^{\circ}$. Khatir (2006) menyatakan bahwa salah satu parameter kunci dalam pengembangan desain rancangan hoper yakni sudut kemiringannya (angel of refuse). Sudut kemiringan bahan merupakan sudut tenang bahan ketika bahan dijatuhkan pada suatu bidang datar. Sudut tenang sangat dipengaruhi oleh massa jenis dan kandungan air. Sudut tenang menentukan koefesien gesek anatar bahan dengan bidang hopper atau silo.

\section{Hopper untuk campuran ragi tempe dengan kedelai}

Dalam sutu perancangan diperlukan perencanaan berupa gambar kerja mesin atau peralatan yang akan dikembangkan. Gambar kerja menjadi acuan dalam perakitan bagian-bagian mesin sehingga menjadi unit mesin atau alat yang utuh. Manfaat gambar kerja yakni untuk mengurangi kesalahan dalam proses pemotongan bentuk bagian mesin. Adapun gambar kerja hopper penampung campuran ragi tempe dengan kedelai dapat dilihat pada Gambar 2.

Desain hopper yang dikembangkan merupakan rangkaian dari suatu unit mesin pencampur ragi tempe dengan kedelai. Perancangan hopper didesain untuk memudahkan bagi pengerajin tempe dalam proses pengemasan. Ukuran atau

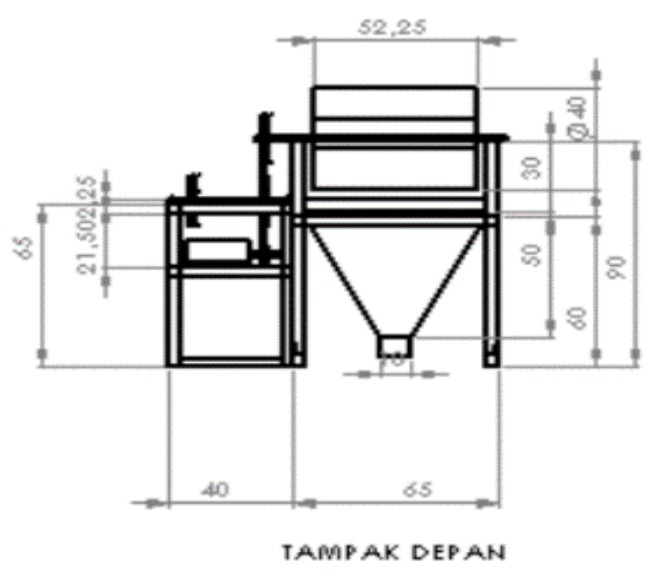

(a)

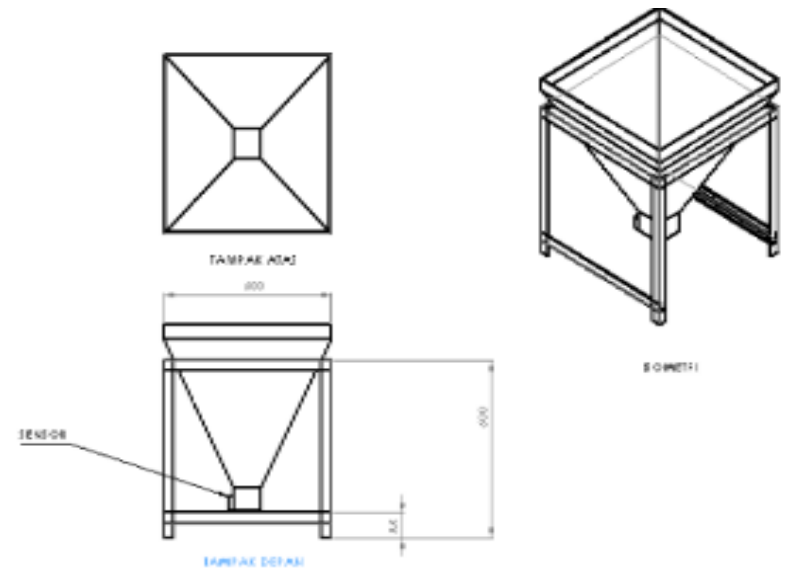

(b)

Gambar 2. (a) Desain mesin pencampur, (b) Desain Hopper pada output 
dimensi hopper yang dikembangkan dengan tinggi $\mathrm{x}$ sisi miring $\mathrm{x}$ diameter yakni $36 \mathrm{~mm}$ x $45 \mathrm{~mm}$ x $50 \mathrm{~mm}$ dengan sudut kemiringin $60^{\circ}$ dengan kapasitas 25 Kg. Sedangkan dimensi keluaran output sebesar 10 x $10 \mathrm{~cm}$. Jenis bahan yang digunakan yakni bahan stainless steel dengan ketebalan $0,3 \mathrm{~mm}$. jenis bahan stainless steel digunakan untuk menjaga tingkat higienis dan bahan tidak mengalami korosi. Hal ini dikarenakan bahan yang ditampung merupakan bahan pangan konsumsi.

Hasil perancangan gambar kerja hopper menjadi acuan proses pembuatan, tahapan proses pembuatan hopper (Andreas, 2011). Dalam pembuatan hopper terdapat beberapa proses pengerjaan, yaitu:

\section{1) Pemotongan}

Bahan yang akan digunakan sebagai bahan baku hopper yakni plat stainless steel berukuran 120 x $240 \mathrm{~cm}^{2}$. Pemotongan dikerjakan dengan mesin potong plat manual sesuai dengan ukuran gambar kerja yang telah disusun. Untuk bagian yang sulit dipotong dengan mesin potong, menggunakan gunting plat. Sedangkan untuk kebutuha rangka, besi kotak dipotong menggunakan mesin gergaji duduk.

2) Pengerolan (tekuk)

Merupakan proses pembentukan untuk membentuk plat menjadi bentuk hopper yang di inginkan. Proses tekuk dilakukan pada sisi-sisi sudut hopper.

3) Penyambungan

Proses penyambungan dilakukan saat proses pengerolan selesai dikerjakan. Hal ini di perlukan untuk menyambung 2 bagian plat agar menjadi bentuk yang di inginkan. Proses penyambungan menggunakan teknik sambungan lipat dan pengelasan titik atau disebut spot welding. Proses ini juga digunakan untuk menggabungkan 2 bagian hopper atas dengan hopper bagian bawah hingga menjadi suatu bentuk hopper yang sesuai gambar kerja.

\section{4) Pemukulan}

Proses pemukulan dilakukan untuk membantu menguatkan sambungan lipat yang diterapkan pada pembuatan hopper ini.

\section{5) Finishing}

Tahap ini berfungsi untuk menyempurnakan hasil pekerjaan agar produk yang telah dibuatberfungsi sebagaimana mestinya. Proses finishing meliputi pemotongan bagian plat yang bersisi tajam atau meratakanya dengan bantuan kikir.

\section{Unjuk kerja Hopper ragi tempe dengan kedelai (Inokulum Tempe)}

Uji kinerja merupakan pengujian terhadap kemampuan alat atau mesin yang dikembangkan untuk menghasilkan produk sesuai fungsi dan kegunaannya. Efektifitas dan kinerja alat atau mesin diuji coba berdasarkan parameter unjuk kerja. Hasil pengukuran unjuk kerja hopper berdasarkan sudut kemiringan hopper yang dikembangkan dapat dilihat pada Tabel 2.

Tabel 2. Nilai Unjuk Kerja Hopper campuran ragi tempe dengan kedelai pada berbagai variasi sudut kemiringan.

\begin{tabular}{llccc}
\hline No & Parameter & \multicolumn{3}{c}{$\begin{array}{c}\text { Sudut Kemiringan } \\
\text { hopper }\end{array}$} \\
& & $30^{\circ}$ & $45^{\circ}$ & $60^{\circ}$ \\
\hline 1 & $\begin{array}{l}\text { Rendemen } \\
(\%)\end{array}$ & 9 & 13 & 18 \\
2 & $\begin{array}{l}\text { Waktu } \\
\text { (detik) }\end{array}$ & 1,14 & 1,46 & 2,15 \\
& & &
\end{tabular}

Berdasarkan Tabel 2 dapat dilihat bahwa hasil pengukuran unjuk kerja hopeer pada berbagai variasi sudut kemiringan dengan masukkan input $10 \mathrm{Kg}$ menunjukkan hasil waktu jatuh dan rendemen yang berbeda. Massa rendemen atau keluaran produk dari lubang output hopper paling besar terdapat pada sudut kemiringan berturut turut $60^{\circ}, 45^{\circ}$, dan $30^{\circ}$ sebesar $1,80 \mathrm{Kg}, 1,32 \mathrm{Kg}$, dan $0,98 \mathrm{Kg}$ 
sehingga waktu yang diperlukan oleh massa bahan jatuh semakin besar. Namun, yang menjadi perhatian adalah persentasi rendeman bahan tertinggi hanya $18 \%$ pada sudut kemiringan $60^{\circ}$.

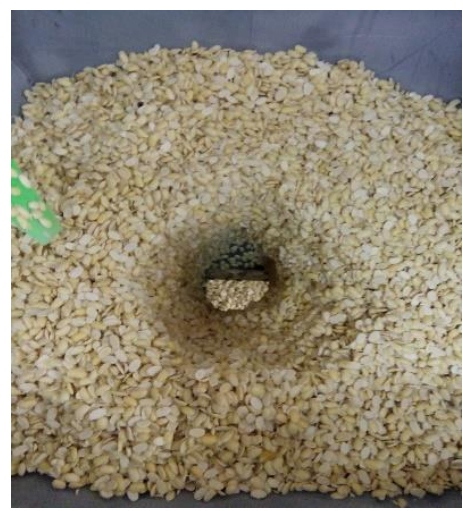

Gambar 3. Proses keluaran bahan dari Hopper

Gambar 3 menunjukkan proses keluarnya inoculum tempe melalui sisi keluaran hopper. Pada proses tersebut menunjukkan terdapat bagian stationary (sisi stagnan bahan yang tidak jatuh ketika lubang keluaran dibuka) seperti yang terlihat pada ilustrasi Gambar 3. pada hopper campuran kedelai dan ragi tempe yang dikembangkan persentase rendemen bahan hanya $18 \%$, hal ini dimungkinkan oleh kadar air bahan yang tinggi yang menyebabkan daya kohesif bahan dan adhesive bahan dengan plat stainless sebagai wadah sangat tinggi. Hal ini sesuai dengan teori yang disampaikan oleh Tsoumis (1991) dalam Sucipto (2009) yang menyatakan bahwa terdapat gaya Tarik menarik antar molekul yang disebabkan adanya ikatan antar partikel atom-atom penyusunnya. Gaya Tarik menarik anatar atom yang sejenis dikenal dengan istilah kohesif sedangkan ikatan antar atom yang tidak sejenis disebut adhesive. Ikatan material dipengaruhi oleh gaya fisik dan kimia bahan. Jika suatu bahan memiliki tingkat adhesive yang tinggi maka akan terjadi suatu absorpsi dimana suatu molekul akan tertarik pada suatu lokasi spesifik. Hal ini menyebabkan gaya Tarik antar partikel akan semakin kuat yng menyebabkan bahan terikat secara kuat dan sulit jatuh.

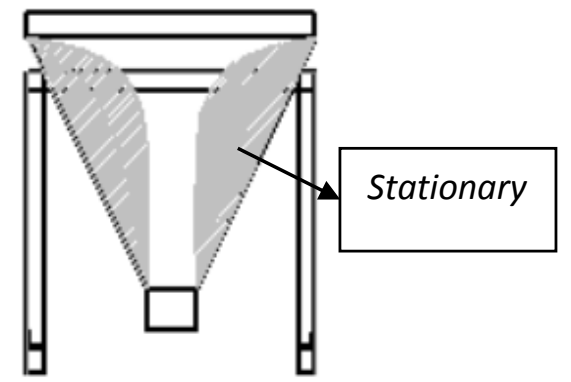

Gambar 4. Ilustrasi titik stationary Hopper campuran Ragi Tempe dengan Kedelai

Perancangan hopper dengan berbagai variasi sudut kemiringan menghasilkan rendemen tertinggi sebesar 18\%, sehingga diperlukan gaya getar yang mampu memecah ikatan antar partikel bahan. Pemberian gaya getar bertujuan untuk memberikan gaya mekanis kepada bahan sehingga ikatan partikelnya bisa terlepas dan produk bisa keluar dengan sempurna melalui sisi keluaran bahan untuk dilakukan proses pengemasan.

\section{KESIMPULAN DAN SARAN}

\section{Kesimpulan}

Adapun kesimpulan dari hasil penelitian ini sebagai berikut:

1. Ukuran atau dimensi hopper yang dikembangkan dengan tinggi $\mathrm{x}$ sisi miring $\mathrm{x}$ diameter yakni $36 \mathrm{~mm}$ x 45 $\mathrm{mm}$ x $50 \mathrm{~mm}$ dengan kapasitas $25 \mathrm{Kg}$.

2. Desain sistem suatu unit Hopper pencampur ragi tempe dengan kedelai yang dikembangkan terbaik memiliki sudut kemiringan $60^{\circ}$.

3. Unjuk kerja hopper menunjukkan rendemen sebesar $18 \%$ dengan masukan input $10 \mathrm{Kg}$.

\section{Saran}

Saran yang disampaikan dari hasil penelitian, yakni diperlukan sistem penggetar pada unit keluaran hopper sehingga bahan dapat keluar secara optimal. 


\section{DAFTAR REFERENSI}

Adawiyah, D.R. (2006). Hubungan Sorpsi Air, Suhu Transisi Gelas, dan Mobilitas Air Serta Pengaruhnya Terhadap Stabilitas Produk Pada Model Pangan. Disertasi. Fakultas Pasca Sarjana. IPB. Bogor

Andreas, A.P. (2011). Proses Pembuatan Hopper dan Penampung Pada Mesin Pencetak Pelet. Tugas Akhir. Univesitas Negeri Yogyakarta. Khatir Yogyakarta.

Keputusan Walikota Mataram. (2009). Keputusan Walikota Mataram Nomor 526/X/2009 tentang Pengembangan Kluster Industri Kerajinan Mutiara, Emas, Perak dan Industri Kecil.

Khatir, Rita. (2006). Penuntun Praktikum Fisiologi dan Teknologi Penanganan
Pasca Panen. Faperta UNSYIAH: Banda Aceh.

Koswara, S. (1995). Teknologi Pengolahan Kedelai Menjadi Makanan Bernutu. Pustaka Sinar Harapan: Jakarta.

Muttalib, S.A., Apriyandita, W., Yulianti, I., Hazmi, R., dan Hartono, M.U. (2017). Rancang Bangun Mesin Pencampur Kedelai dengan Kapang (Ragi Tempe) Pada Industri Rumahan Di Daerah Kota Mataram. Jurnal Ilmiah Rekayasa Pertanian dan Biosistem 5 (1): 316 - 320.

Saddam. (2012). Rancangan Mesin Pemipih Dan Pemotong Adonan Mie. Proyek Akhir. Universitas Negeri Yogyakarta. Yogyakarta Sucipto, T. (2009). Teori Adhesif Spesifik Perekat. Diakses dari https://usu.ac.id/search.EquAyytl_8 k. 10 Nopember 2018. 